\title{
Politizando as escalas urbanas: jurisdição, território e governança no Estatuto da Metrópole
}

\author{
Politicizing urban scales: jurisdiction, territory \\ and governance in the Metropolis Statute
}

Thiago de Azevedo Pinheiro Hoshino [l]

Rosa Moura [II]

\section{Resumo}

0 Estatuto da Metrópole (lei n. 13.089/2015) é objeto de análise exploratória neste artigo. 0 diploma tem potencial para promover uma reconfiguração político-jurídica nos sentidos da governança interfederativa. Por isso mesmo, mobiliza atores assimétricos que disputam o reescalonamento da política urbana. Tanto assim que o Estatuto já sofreu substanciais supressões quanto aos prazos para adequação institucional e respectivas sanções em caso de descumprimento. Tomando esse processo como um caso emblemático, os autores defendem a rentabilidade teórica do conceito de "política da escala" para a compreensão da natureza dos conflitos suscitados e fazem uma reflexão crítica sobre os dispositivos escalares em sua relação com os novos instrumentos disponíveis para o trato da metropolização brasileira.

Palavras-chave: Estatuto da Metrópole; jurisdição; política da escala; governança interfederativa, direito à cidade.

\begin{abstract}
The Estatuto da Metrópole (Metropolis Statute, Law 13089/15) is the object of an exploratory analysis in this paper. Such Statute has potential for promoting a legal-political reconfiguration in the field of interfederative governance. That is why it mobilizes asymmetric actors who dispute the rescaling of urban politics. So much so that the Estatuto da Metrópole has already suffered substantial suppressions regarding deadlines for institutional adaptation and respective sanctions in case of delay. Viewing this process as an emblematic one, the authors make a case for the concept of "politics of scale", useful to the theoretical comprehension of the nature of the conflicts arisen, and offer a critical account of scalar devices and their relationship to the new tools for dealing with the Brazilian metropolization.
\end{abstract}

Keywords: Estatuto da Metrópole; jurisdiction; politics of scale; interfederative governance; right to the city. 
A liberdade da metrópole nasce da construção e reconstrução que a cada dia ela opera sobre si mesma e de si mesma.

(Negri, 2010)

\section{Introdução: um estatuto para as metrópoles brasileiras?}

A questão metropolitana, ambígua e metonimicamente, permaneceu periférica na redação final do Estatuto da Cidade (lei n. 10.257/2001), marco central da política urbana brasileira a expandir os horizontes do art. 182 da Constituição de 1988. Embora haja comparecido ao longo das versões anteriores do diploma e dos debates que se promoveram ao longo de sua tramitação, o tema terminou restrito às diretrizes gerais e à regra de participação popular nos organismos gestores regionais, inscrita no art. 45. Diante desse cenário, e por mais incongruente que pudesse parecer (haja vista que "cidade" e "metrópole" estão longe de serem categorias desconexas), um novo estatuto parecia necessário, um Estatuto da Metrópole. Se, contudo, a metrópole do Estatuto reflete o status das metrópoles brasileiras é uma das questões que suscitamos, conscientes de que apenas um programa mais amplo e ambicioso de investigação poderá respondê-la a contento.

Foi assim que, em maio de 2004, o deputado Walter Feldman submeteu à Câmara dos Deputados projeto de lei (PL 3.460/2004) com o fito de, nas palavras da própria ementa, instituir diretrizes para a Política Nacional de
Planejamento Regional Urbano, criar o Sistema Nacional de Planejamento e Informações Regionais Urbanas e dar outras providências. Nesse mesmo ano, o projeto foi analisado pelas comissões de Desenvolvimento Urbano, de Finanças e Tributação, de Constituição e Justiça e de Cidadania, da Câmara dos Deputados, porém, em julho de 2007, sem emendas, foi arquivado pela primeira vez. Desarquivado, foi objeto de análise em 2008 por uma Comissão Especial composta pelas comissões do Meio Ambiente e Desenvolvimento Sustentável e de Desenvolvimento Econômico, Indústria e Comércio, além das já citadas; no entanto, também nesse caso, o debate não prosperou. Em janeiro de 2011, o deputado Zezéu Ribeiro (PT-BA) foi designado como relator do projeto e, a partir de então, uma sequência de reuniões, seminários e discussões regionais se desenrolou, resultando em um substitutivo bastante detalhado, construído participativamente. Ao fim e ao cabo, em sua versão final, com o parecer do relator, o substitutivo foi aprovado por unanimidade pela casa legislativa. ${ }^{1}$

No Senado Federal, o trâmite do projeto foi muito mais célere. Remetido pela Câmara dos Deputados em março de 2014, já em dezembro desse ano é encaminhado para sanção presidencial, ocorrida no dia 12 de janeiro de 2015. 
A construção do substitutivo levou em consideração as muitas críticas ao projeto original, de 2004, que obteve maior resistência no tocante às definições de "região metropolitana" (RM) e de "aglomeração urbana" (AU) e no fato de, em lugar de tratar especificamente da dimensão metropolitana, estabelecer as diretrizes para a Política Nacional de Planejamento Regional Urbano e desenhar o Sistema Nacional de Planejamento e Informações Regionais Urbanas, matéria que mereceria marco normativo próprio, dada sua abrangência (Moura e Firkowski, 2008; Moura e Carvalho, 2012; e Torreão, 2012).

Não só nesses aspectos o projeto tornou-se extemporâneo, pois, enquanto dormitava nas arcadas de Brasília, lançaram-se as bases de inúmeras políticas setoriais nacionais, na área da habitação (por exemplo, o Sistema Nacional de Habitação de Interesse Social assentado na lei $n .11 .124 / 2005)$, do saneamento (Política Nacional de Saneamento Básico, organizada pela lei n. 11.445/2007), da mobilidade urbana (Sistema Nacional de Mobilidade Urbana, previsto na lei n. 12.587/2012), da defesa civil (Política Nacional de Proteção e Defesa Civil da lei n. 12.608/2012), etc. Além disso, o estado brasileiro, ao longo dessa década, inaugurou um novo ciclo de social-desenvolvimentismo e formulou políticas e programas, em vários âmbitos, que impactaram sobremaneira o espaço urbano-regional, tais como o Programa de Aceleração do Crescimento (PAC) e o Programa Minha Casa Minha Vida (MCMV).

Tais inconsistências evidenciaram a necessidade de revisão da proposta original, ao mesmo tempo que tornavam ainda mais urgentes as regras que orientassem a instituição de "regiões metropolitanas" no País e que recuperassem seu objetivo fundamental: o exercício das Funções Públicas de Interesse Comum (FPICs). Desde a Constituição Federal de 1988, que franqueou, aos estados, a competência para a instituição de RMs, AUs e microrregiões (MRs), o número de RMs no País elevou-se das 9 unidades instituídas por lei federal (n. 14/1973 e 20/1974) para mais de 70, distribuídas entre os estados da federação; a grande maioria, seguramente, sem os predicados mínimos que lhes atribuíssem verdadeira natureza metropolitana. Essa proliferação casuística e o descaso reiterado, por parte dos estados, para com critérios que distinguissem aglomerações polarizadas por metrópoles daquelas que correspondem a simples aglomerações urbanas, implicaram grandes obstáculos à promoção de ações nesse setor, sobretudo por parte do governo federal.

Ademais, entre as RMs institucionalizadas, poucas tiveram como motivação o efetivo exercício das FPICs, e um número menor ainda concretizou a composição de estruturas de governança democrática (Observatório, 2009). Traduzindo em dados, do ponto de vista de sua operacionalização e efetividade, também se constatou, ao lardo dos quarenta anos de experiência brasileira, que somente um terço das RMs possui ou está elaborando plano metropolitano; $80 \%$ possui conselho deliberativo constituído, mas apenas 33\% prevê a participação da sociedade civil; $73 \%$ possui fundo de contribuição, porém $60 \%$ destes nunca foram alimentados (Costa e Tsukumo, 2013).

Ou seja, criar RMs tornou-se uma prática pouco eficaz para assumir os desafios mais típicos das aglomerações - a gestão do transporte público, do saneamento básico, da gestão de resíduos sólidos, entre outros - que exigem 
a atuação coordenada entre municípios e entre instâncias de governo, com participação da sociedade. Sabidamente, muitos dos dilemas estruturais a serem enfrentados pelas cidades brasileiras, expressos nas crises da mobilidade, da habitação, da água, estão intrinsecamente associados às fragilidades do planejamento e da gestão metropolitanos. As Jornadas de Junho de 2013, que inundaram as ruas por todo 0 País, lançaram luz sobre parte dessas questões, embora os movimentos sociais e a academia, há muito, já viessem insistindo na necessidade de repensá-las em nova escala e com novas ferramentas. Nesse sentido, as recentes manifestações corroboram os diagnósticos teóricos, que confluem na interpretação sobre o esvaziamento do planejamento metropolitano após o processo de redemocratização brasileira, no final da década de 1980:

0 debate brasileiro sobre a governança metropolitana após 1990 é emblemático ao tratar desse paradoxo. Em grandes linhas, assinala que, após o esvaziamento do planejamento metropolitano tecnocrata, centralista e autoritário, que caracterizava o Regime Militar, emergiu um vazio institucional. Isto ocorreu porque, no bojo da redemocratização e da descentralização, os novos atores, principalmente os prefeitos eleitos e os movimentos sociais, não pautaram uma agenda metropolitana. No debate sobre a governança, a região metropolitana ficou "órfã" no pacto federativo brasileiro. Sua trajetória é caracterizada pela proliferação de arranjos como os consórcios setoriais - particularmente em áreas temáticas como a saúde -, pelo esvaziamento ou extinção das autarquias estaduais, criadas nos anos 1970, e pela ocorrência de raríssimas inovações. (Klink, 2013, p. 83)
Assim, a elaboração do substitutivo final do projeto de lei teve como preocupação central enfrentar esses gargalos. Desde clarificar conceitos, definir instrumentos, apontar fontes de recursos, até buscar elementos que garantissem a construção de estruturas mais estáveis de gestão com mecanismos integradores e participativos, tornando a proposta mais refinada e precisa quanto ao objeto.

Aprovada, com vetos bastante polêmicos da presidência, e publicada em janeiro de 2015, essa última versão teve curta sobrevida. Um dia antes de seu aniversário de três anos, a medida provisória 818/2018 promoveu alterações substanciais nas disposições referentes aos prazos para elaboração dos PDUls para as RMs e AUs preexistentes ao Estatuto (art. 21, I 'b'), prorrogando-os para dezembro de 2021. Em seguida, a lei n. 13.683/2018, advinda da conversão da mencionada MP, terminou por revogar integralmente 0 art. 21, lançando por terra tanto os prazos quanto as hipóteses de improbidade administrativa por seu descumprimento. As supressões de iniciativa do Poder Legislativo demonstram não só a recalcitrância quanto a possíveis sanções, mas também os conflitos em torno da questão metropolitana e do reescalonamento da política urbana.

Numa abordagem analítica, enfatiza-se que o que está em jogo aqui é a produção do espaço e as formas como se territorializa o estado. Assim, apesar dos estudos recentes sobre o Estatuto da Metrópole e sobre os processos que ele dinamizou, em distintas localidades, faltam análises sobre o potencial das novas normas para deslocar ou, no mínimo, tensionar campos de competência e jurisdições. Essas normas são aqui interrogadas enquanto 
dispositivos escalares. A intenção do presente texto é justamente enfrentar, de modo exploratório, algumas das questões que atravessam a edição, a implementação e mesmo os retrocessos do diploma, elucidando, todavia, que elas não são fruto de pesquisa empírica estrutura$\mathrm{da}$, mas se inserem num conjunto mais amplo de reflexões da agenda coletiva da Rede do INCT Observatório das Metrópoles.

\section{Dispositivos escalares: critérios de institucionalização e sentidos da regionalização}

O escopo primeiro do Estatuto da Metrópole é a regulamentação das unidades territoriais urbanas, ou seja, aglomerações urbanas de natureza metropolitana ou não metropolitana e sua institucionalização como Regiões Metropolitanas (RMs) ou Aglomerações Urbanas (AUs) para o exercício das funções públicas de interesse comum. E, para não dar margem a dúvidas, 0 art. $2^{\circ}$ comporta esse relevante arcabouço conceitual: aglomeração urbana, metrópole, região metropolitana, função pública de interesse comum, plano de desenvolvimento urbano integrado, gestão plena, governança interfederativa. Todos recebem definição legal e passam a ser institutos jurídicos, além de categorias teóricas. Deve-se salientar que, para angariar status de metrópole, o núcleo da unidade deve envolver, no mínimo, a área de influência de uma capital regional, conforme classificação do Instituto Brasileiro de Geografia e Estatística. Essa exigência poderia ser mais restritiva, porém está, em termos gerais, adequada à grande diversidade da rede urbana brasileira, na qual, em determinadas regiões de menor densidade de ocupação, centros regionais detêm efetivamente a condição de metrópoles. Com base nessa definição, uma "região metropolitana" só poderá ser instituída em relação a uma aglomeração urbana que configure uma metrópole. Mais do que isso, a RM instituída mediante lei complementar estadual que não atenda a esse requisito será enquadrada como aglomeração urbana para efeito das políticas públicas a cargo da União (art. 15). Além das RMs e AUs, no $§ 10$, I do art. $1^{\circ}$, fica claro que suas disposições se aplicam, subsidiariamente, também às microrregiões instituídas pelos estados com fundamento em funções públicas de interesse comum com características predominantemente urbanas.

Vem a calhar a tentativa de disciplinar com critérios "técnicos" a formatação das unidades territoriais (notem-se, todavia, as aspas que empregamos para, justamente, não economizar ressalvas quanto à dimensão intrinsecamente política de todas as decisões ditas "técnicas"). Sejam regiões supranacionais, sejam transmunicipais, o próprio conceito de região responde a geometrias variáveis e lutas tanto discursivas quanto substantivas, por seu mapeamento, nomeação, agenciamento e desenvolvimento:

No geral, as geometrias variáveis de fronteiras econômicas e políticas tornam difícil para as autoridades competentes imaginar, construir e governar uma economia regional em termos de fronteiras pré-definidas. Ao contrário, as regiões são mais bem definidas em termos de sua co-constituição por fatores discursivos e materiais que, juntos, fornecem-lhes uma identidade imaginada mais ou menos coerente, assim como uma estruturação 
social. Isto coloca o problema de como demarcar uma região como uma matriz espaço-temporal significativa e viável de ação social e da ordem institucional dentro de um nexo mais amplo de relações sociais. Regiões estão sujeitas a lutas discursivas sobre o mapeamento e a nomeação (Jenson, 1995; Paasi, 2004; Sidaway, 2002) que são análogas às lutas anteriores sobre a formação de comunidades nacionais imaginadas (Anderson, 2008); e por lutas mais substantivas sobre o seu desenvolvimento social, material e sobre sua institucionalização espaço-temporal. (Jessop, 2018, p. 47)

No que se refere às categorias das unidades territoriais urbanas, não está claro na Lei o destino das dezenas de regiões e aglomerações já criadas. Pode-se interpretar que, como decorrem da competência dos estados-membros, a eles cabe sua manutenção, adequação ou revogação. Independentemente de corresponderem ou não aos conceitos estabelecidos, entende-se que como unidades territoriais urbanas institucionalizadas, terão direito a apoio governamental desde que comprovem a realização da gestão plena, elemento que será tratado a seguir.

Diante do amplo universo de unidades institucionalizadas como regiões metropolitanas, muitos esforços foram realizados para identificar qual a porção de fato representa o território correspondente ao fenômeno socioespacial da unidade (Ipea, 2002; Observatório, 2013). Observa-se que a base conceitual positiva pelo Estatuto não aporta critérios que identifiquem esse recorte, desembocando na necessidade da realização integrada das FPICs. Ribeiro, Santos Junior e Rodrigues (2015) reconhecem um avanço conceitual, mas criticam o fato de o Estatuto da Metrópole legitimar as imprecisões e os equívocos consolidados pelas leis estaduais vigentes, ao não determinar expressamente sua revisão quanto à delimitação das RMs e AUs. Não destoando dessa tendência, o governo do estado do Paraná afoitamente sancionou, no mesmo dia da publicação do Estatuto da Metrópole (13 de janeiro de 2015), leis que instituíram mais quatro regiões metropolitanas, num nítido esforço para esquivar-se dos novos critérios condicionantes (Moura e Hoshino, 2015). A hipertrofia desses entes é escancarada e se materializa em casos extremos, como o do estado de Santa Catarina, cujos 295 municípios se acham, em sua totalidade, inseridos formalmente em unidades territoriais dessa espécie. Um estado, pode-se dizer, metropolitano. Ainda, a literatura sublinha a deficiência de parâmetros para identificar o território funcional das unidades, "compreendido pelos municípios que efetivamente têm relações de interpendência no plano da produção, do mercado de trabalho e da vida coletiva" (Ribeiro, Santos Junior e Rodrigues, 2015, p. 3).

Outra lacuna diz respeito ao campo de aplicação da nova lei, qual seja: as RMs, AUs e MRs. Há que se considerar que, tanto conceitual como pragmaticamente, a dinâmica da metropolização brasileira não se esgota nessas três categorias constitucionais, dado que vem configurando espacialidades complexas, a desenvolverem relações que transcendem os limites da porção mais adensada da aglomeração. Grandes regiões urbanas, contínuas e descontínuas, que aglutinam regiões metropolitanas, aglomerações e centros urbanos, exigem regulação apropriada. É exemplo disso a macrometrópole de São Paulo, que abrange, em sua unidade, uma rede de aglomerações urbanas, muitas institucionalizadas como RMs 
e AUs. Essa realidade impõe que se vislumbrem outras morfologias - arranjos espaciais, cidades em rede, configurações difusas, aglomerações transfronteiriças, entre outras. Mais do que isso, exige que se incorporem novas escalas urbano-regionais que caracterizam muitas dessas aglomerações, na medida em que mesclam as naturezas urbana, metropolitana e regional em arranjos híbridos. Essa lacuna encontra consonância na observação de Ribeiro, Santos Junior e Rodrigues (ibid., p. 1), que será retomada adiante:

Esse ponto é fundamental, pois o Estatuto deixou de regulamentar as bases necessárias para a construção de efetiva capacidade de governabilidade das metrópoles. Tais bases dizem respeito à construção de referências espaciais para um arcabouço institucional que permita dotar a autoridade pública (ou instância governativa) metropolitana de legitimidade funcional, social, política e institucional, sem o que toda ação pública sobre este território será incapaz de enfrentar os desafios societários nelas concentrados.

0 problema agrava-se em face da unilateralidade do processo de instituição das unidades territoriais, viés que permaneceu na Constituição Federal de 1988 e que foi impresso, enfim, ao Estatuto da Metrópole. Originalmente, a Constituição de 1967 alocava a criação de novas regiões metropolitanas (RMs) entre as competências da União, conforme previsto no art. $157, \S 10^{\circ}$, conteúdo que, todavia, migrou, nas reformas subsequentes, para 0 art. 164:

Art. 164. A União, mediante lei complementar, poderá para a realização de serviços comuns, estabelecer regiões metropolitanas, constituídas por municípios que, independentemente de sua vinculação administrativa, façam parte da mesma comunidade socioeconômica.

Já, na Constituição de 1988, podem-se observar importantes inovações quanto à matéria, agora insculpida no art. $25, \S 3^{\circ}$, sendo 0 deslocamento da competência para os estados-membros uma das principais mudanças:

Art. 25. Os Estados organizam-se e regem-se pelas Constituições e leis que adotarem, observados os princípios desta Constituição.

$\S 3^{\circ}$ Os Estados poderão, mediante lei complementar, instituir regiões metropolitanas, aglomerações urbanas e microrregiões, constituídas por agrupamentos de municípios limítrofes, para integrar a organização, o planejamento e a execução de funções públicas de interesse comum.

A despeito do fortalecimento da pauta municipalista na nova Carta Magna e do vetor administrativo descentralizador por ela encampado, seu influxo não pareceu reformular o papel apassivado dos municípios no que respeita ao ato inaugural de instituição das unidades territoriais regionalizadas (regiões metropolitanas, aglomerações urbanas e microrregiões). Já sob a antiga lei fundamental elucidava Grau (1974, pp. 104-105):

Para logo se vê, portanto, que a norma originariamente disposta pela Constituição de 1967, consubstanciada no artigo 164 da que lhe sucedeu, expressa uma modalidade de relacionamento não voluntário, mas compulsório, entre unidades político-administrativas nas regiões metropolitanas. Quando as unidades político-administrativas se relacionam em função de vínculo voluntário, a qualquer momento poderá ser rompido o acordo 
entre elas estabelecido [...]. No que respeita, porém, ao novo tipo de relacionamento gerado pela disposição constitucional, a sua compulsoriedade originária implica que não possa ser rompida a associação que surge entre as unidades político-administrativas.

É dizer, muito embora tenham avançado os mecanismos de cooperação e consorciamento entre entes públicos nos últimos anos, pouco se alterou na lógica da instituição forçosa e unilateral das unidades territoriais regionais. Assim como figurava na controversa Constituição de 1967 e na doutrina que a encarnou, o entendimento majoritário segue sendo no sentido da "compulsoriedade originária" do tipo de associação político-administrativa que nasce com a instituição das unidades regionais, especialmente as RMs. Os entes locais continuam coadjuvantes nesse momento, sendo integrados compulsoriamente, já não pela União, mas pelos estados-membros, sem grande possibilidade de opinar previamente sobre tal medida ou de participar da concepção inicial de uma nova $R M, A U$ ou $M R$, inclusive no tange às suas fronteiras geográficas. É o que se infere da jurisprudência do Supremo Tribunal Federal (a Corte Constitucional brasileira), dispensando anuência prévia ou de participação dos municípios na elaboração da lei estadual que inaugura uma RM (Brasil, 1998 e 2002).

É autorizado afirmar, portanto, que, embora o Estatuto da Metrópole disponha de critérios técnicos para a confecção de novas unidades territoriais, sobrevive um espaço de discricionariedade política manifesto, por exemplo, na eleição das FPICs a serem realizadas pelas RMs, AUs ou MRs. Nesse espaço de decisão política, hoje, não têm voz os municípios que serão abarcados por essas unidades, pois acham-se legalmente excluídos do ato primeiro de instituição delas. Todavia, como tal ato deve se concretizar através de lei complementar, as autoridades municipais poderão recorrer a seus representantes no Poder Legislativo Estadual para influir nesse processo, inclusive quanto à delimitação geográfica da unidade territorial e de seus objetivos precípuos.

Isso porque o capítulo II da lei n. 13.089/ 2015 traz requisitos para a formalização das RMs e AUs, determinando que as leis complementares estaduais que instituirão essas unidades prevejam, além dos municípios integrantes, as FPICs que justificam a medida, a estrutura mínima de governança interfederativa e os meios de controle social da organização, do planejamento e da execução das FIPC (art. $5^{\circ}$, I a IV). Nesse quesito, a exigência de embasar em leituras de agências especializadas e nacionais, como o IBGE, a delimitação territorial e 0 rol de funções comuns eleitas como prioritárias para cada unidade (art. $5^{\circ}, \S 1^{\circ}$ ) representa um avanço nada desprezível, ao viabilizar o controle (da sociedade como dos órgãos de fiscalização externa) sobre a motivação dos atos das autoridades políticas, reduzindo o espaço da pura arbitrariedade e da barganha. Muito embora sempre se possa questionar o quão "técnicos" são quaisquer critérios nessa matéria, do ponto de vista estritamente jurídico, a exposição de motivos dos respectivos projetos de lei complementar seria o espaço ideal para sistematizar esse conjunto de estudos e diagnósticos em que a proposta se sustenta. Caso contrário, a própria fundação da unidade seria passível de questionamento. 


\section{Dispositivos escalares: funções públicas e interesse "comum"}

Visto por outro prisma, a compulsoriedade na integração regional tem certa razão de ser. Se, por um lado, ela traz algo de impositivo, em certa medida "autoritário", como argumentam alguns, por outro, ela parte de uma acertada análise sobre os limites do consorciamento e da cooperação entre distintos entes federativos. A urgência em racionalizar e tornar mais eficientes o planejamento e a gestão das FPICs em escala metropolitana demanda respostas rápidas do poder público, as quais muitas vezes não podem suportar os chamados "custos transacionais" das inúmeras tentativas de associação voluntária (custos não apenas financeiros, mas também políticos e de tempo).

Importante notar que o Estatuto da Metrópole conceitua FPIC como "política pública ou ação nela inserida cuja realização por parte de um município, isoladamente, seja inviável ou cause impacto em municípios limítrofes" (art. $2^{\circ}$, II). Não demonstrou, o legislador, intenção de relacionar taxativamente nem de esgotar tais funções, cuja variedade somente 0 tempo, a experiência concreta e as correlações de força local-regional poderão qualificar. Com isso, deixa em aberto a distinção entre "interesse local" (que continua sob tutela municipal) e "interesse comum" (que passa a ser de competência metropolitana), uma linha tênue, em muitas situações. 0 critério do "impacto" regional ou da "inviabilidade", assim, talvez esconda mais do que revela, abrindo outra rodada de questionamentos:
De que inviabilidade se trata? Institucional, técnica ou financeira? Em todo caso, na prática, os próprios critérios que devem ser observados para a criação de uma RM ou uma $\mathrm{AU}$ indicam a existência de relações de interdependência que promovem impacto em todos os municípios. A questão, então, relaciona-se tanto com a capacidade dos entes como com a natureza do serviço e a busca pela melhor forma (mais eficiente, com maior escala e modicidade tarifária e melhor atendimento) para a população. Registra-se, ainda, que a lei n. 13.089/2015 parece ter utilizado a expressão "campos funcionais" como sinônimo de FPICs. A primeira expressão, contudo, embora não esteja na CF, indica que cada FPIC pode apresentar uma dimensão territorial diversificada, a depender dos setores e dos atores abarcados pelos diversos campos funcionais. Ilustrativamente, a configuração do campo funcional da mobilidade urbana não necessariamente converge, de modo integral, com o do saneamento básico. (Santos, 2018, p. 466)

Sob essa ótica, é possível antever que, se levada às últimas consequências, a redistribuição das competências e titularidades para a consecução das FPICs consistirá num dos focos nevrálgicos das disputas políticas. Tomemos o exemplo do controle do uso e ocupação do solo urbano: se já é conflituosa sua normatização dentro de um único município, quem dirá o zoneamento das RMs e AUs. Até que ponto essa regulação supramunicipal colide com a autonomia constitucional dos municípios para o ordenamento territorial (art. 30, VIII da CF/88)? Qual o grau aceitável de direcionamento e detalhe de um macrozoneamento metropolitano, agora vinculante para 
os demais entes? Ou, inversamente, o que se enquadraria como de interesse metropolitano em um zoneamento municipal?

0 ordenamento territorial é uma atividade estatal emblemática de análise, pois, na contramão do que se tem, amiúde, advogado, as funções públicas de interesse comum não se restringem à prestação de serviços. Nesse sentido, é significativo o avanço do Estatuto da Metrópole ao englobar macrozoneamento da unidade territorial urbana (art. $12, \S 1^{\circ}, \mathrm{II}$ ) no conteúdo mínimo do Plano de Desenvolvimento Urbano Integrado (PDUI). Explicitou-se, aqui, a necessária coesão dinâmica, sistematicidade e transescalaridade do ordenamento territorial, que deve compatibilizar (deve, e não pode, porque de poder-dever se trata) $)^{2}$ diversos níveis de planejamento e gestão, entre eles 0 urbano-regional. Esse reescalonamento das FPICs, por certo, é uma das apostas atuais para alavancar a eficiência (art. 37, caput, CF/1988) da administração pública e assegurar, na hipótese mesmo de concessão dos serviços públicos a empresas particulares, a sua adequada prestação quanto às condições de regularidade, continuidade, segurança, atualidade, generalidade e modicidade das tarifas.

Mesmo antes da edição de um marco específico, iniciativas como a da Região Metropolitana de Belo Horizonte já haviam seguido por esse caminho, no qual até mesmo a universidade foi engajada para a construção de proposta de macrozoneamento regional:

0 uso do solo metropolitano é uma função pública de interesse comum preconizada pela Lei Complementar no 89/2006, que dispõe sobre a Região Metropolitana (RM) de Belo Horizonte, e a atuação dos seus órgãos de gestão deve abranger ações que assegurem a utilização do espaço metropolitano sem conflitos e sem prejuízo à proteção do meio ambiente. [...] 0 controle do uso do solo metropolitano é atribuição da Agência de Desenvolvimento da RM de Belo Horizonte (Agência RMBH), por meio da emissão de diretrizes e da concessão de anuência prévia aos parcelamentos. Ela possui também a prerrogativa de exercer o poder de polícia estadual para o controle da expansão urbana na RM de Belo Horizonte: o poder de polícia preventivo no caso da anuência prévia e o poder de polícia corretivo no caso da fiscalização. Para além dessas atividades de rotina, a Agência RMBH tem buscado atuar em atividades de planejamento territorial. No final de 2013, a Universidade Federal de Minas Gerais (UFMG) foi contratada, com recursos do fundo de desenvolvimento metropolitano, para elaborar o macrozoneamento da região, cuja implementação terá retaguarda jurídica de um projeto de lei (PL) em tramitação na Assembleia Legislativa de Minas Gerais. (Drummond e Silveira, 2014, pp. 85-86)

Controvérsias provavelmente emergirão também na prestação de determinados serviços públicos essenciais. Levando-se em conta que o transporte coletivo, o saneamento básico, entre outros serviços, podem ser mais eficientes e inclusivos se planejados e geridos em nível regional ou metropolitano, o novo modelo, em certa medida, coloca em xeque 0 arraigado municipalismo nas políticas setoriais. Os municípios deverão, pelo art. 10, §3 da lei n. 13.089/2015, compatibilizar seus planos diretores com as novas diretrizes dos PDUI. Contudo, olvidou o legislador todos os demais planos (Planos de Saneamento Básico, Planos de Mobilidade Urbana, Planos de Gestão de Resíduos Sólidos, Planos Locais de Habitação 
de Interesse Social, etc.), os quais não restaram sujeitos à mesma obrigatoriedade.

0 cenário avulta ainda mais complexo nas hipóteses de prestação por delegação. Os serviços caracterizados como FPIC submeter-se-ão a novo regime jurídico, não mais passível de concessão fragmentada, o que, espera-se, impactará na sua modelagem administrativo-financeira e se refletirá na abertura de novas licitações. Nesse ponto, outro precedente do qual não se pode afastar é a ação direta de inconstitucionalidade n. 1.842/RJ, julgada em março de 2013 pelo Supremo Tribunal Federal. Nela, a Corte reconheceu que, para a execução das FPICs, no contexto metropolitano ou de aglomerado urbano, o poder concedente e a titularidade do serviço (no caso, de saneamento básico) são do colegiado formado pelos municípios e pelo estado federado, compartilhando seu planejamento e gestão. É ilustrativo transcrever o seguinte trecho da decisão:

Nada obstante à competência municipal do poder concedente do serviço público de saneamento básico, 0 alto custo e o monopólio natural do serviço, além da existência de várias etapas - como captação, tratamento, adução, reserva, distribuição de água e o recolhimento, condução e disposição final de esgoto que comumente ultrapassam os limites territoriais de um município, indicam a existência de interesse comum do serviço de saneamento básico. A função pública do saneamento básico frequentemente extrapola o interesse local e passa a ter natureza de interesse comum no caso de instituição de regiões metropolitanas, aglomerações urbanas e microrregiões, nos termos do art. $25, \S 3^{\circ}$, da Constituição Federal. [...] A instituição de regiões metropolitanas, aglomerações urbanas ou microrregiões pode vincular a participação de municípios limítrofes, com 0 objetivo de executar e planejar a função pública do saneamento básico, seja para atender adequadamente às exigências de higiene e saúde pública, seja para dar viabilidade econômica e técnica aos municípios menos favorecidos. Repita-se que esse caráter compulsório da integração metropolitana não esvazia a autonomia municipal. [...] 0 interesse comum é muito mais que a soma de cada interesse local envolvido, pois a má condução da função de saneamento básico por apenas um município pode colocar em risco todo o esforço do conjunto, além das consequências para a saúde pública de toda a região. 0 parâmetro para aferição da constitucionalidade reside no respeito à divisão de responsabilidades entre municípios e estado. É necessário evitar que 0 poder decisório e o poder concedente se concentrem nas mãos de um único ente para preservação do autogoverno e da autoadministração dos municípios. Reconhecimento do poder concedente e da titularidade do serviço ao colegiado formado pelos municípios e pelo estado federado. A participação de cada Município e do Estado deve ser estipulada em cada região metropolitana de acordo com suas particularidades, sem que se permita que um ente tenha predomínio absoluto. (Brasil, 2013, pp. 2-3)

A decisão tomada pela Corte Constitucional desdobra-se em outras problemáticas. A partir de sua publicação, ela torna-se um paradigma não só para o poder executivo dos vários entes da federação, mas também para a interpretação do próprio Estatuto da Metrópole, a saber, fixa as bases sobre as quais ele deverá ser implementado. Importante, destarte, compreender como se forma esse "colegiado" 
de municípios e estado, explorando como se (re)distribuem a autoridade e o poder decisório dentro dele, para evitar concentração desproporcional de qualquer das partes. A disputa centra-se, portanto, na nomeação, como anuncia Jessop (2018), isto é, a disputa pelo direito de definir no que consiste e até onde vai o interesse "comum", pilar (amiúde tão instável) da comunidade política metropolitana.

\section{Dispositivos escalares: partilha de poder e governança interfederativa}

Atingir esse reequilíbrio interfederativo é o escopo do capítulo III da lei n. 13.089/2015, que reitera princípios do Estatuto da Cidade, enfatiza a prevalência do interesse comum sobre 0 local, com respeito às peculiaridades e à autonomia dos entes, o compartilhamento de responsabilidades e a busca do desenvolvimento sustentável. Como diretrizes, reforça a implantação de processo permanente e compartilhado de planejamento e de tomada de decisão, observado o imperativo de gestão democrática das cidades. Para tanto, estratégias como rateio de recursos e alinhamento orçamentário dos entes envolvidos na governança interfederativa podem ser empregadas.

Como estrutura básica da governança interfederativa de RMs e AUs, o texto alude a uma instância executiva, uma instância colegiada deliberativa com representação da sociedade civil, uma organização pública com funções técnico-consultivas e um sistema integrado de alocação de recursos e de prestação de contas (art. 8). Conquanto a inovação seja bem-vinda, ela esbarra no descompasso entre a realidade do atual estágio da urbanização brasileira e o modelo de federação encarnado na Constituição de 1988 (suas fronteiras político-administrativas), sendo esse tema de uma agenda maior e constantemente adiada de repactuação federativa. 0 Estatuto da Metrópole, nesse sentido, vem tensionar o velho pacto e reabrir uma chaga historicamente alimentada por rixas partidárias e desencontros entre mandatos vizinhos, que agora terão de ser superados ou, no mínimo, amenizados para atender ao comando legal.

Do ponto de vista teórico-comparativo, 0 federalismo e os sistemas federativos são bastante ilustrativos como artefatos de construção política das escalas (Delaney e Lettner, 1997). A arena de contestação e disputa por essas escalas é central no debate metropolitano, a ponto de Cox (2010, p. 216) assinalar que "a preocupação com a governança metropolitana é a de construir instituições em novas escalas geográficas; instituições que irão inevitavelmente instaurar tensões em face daquelas que já existem em outras escalas". Em outras palavras, a alavancagem da governança interfederativa em nível urbano-regional implica enfrentar a fragmentação jurisdicional do estado, isto é, a incompatibilidade entre a cidade real (dinâmicas do espaço vivido) e a cidade formal (fronteiras político-administrativas). A discussão não é nova e passa, entre outras, pela assimetria entre volumes de arrecadação (quanto se ganha) e cargas de atribuições (quanto se gasta) de cada esfera federativa brasileira (Arretche, 2004). Muito embora o governo federal tenha buscado equacionar o problema nos últimos anos (e nesse sentido é sintomática a criação de uma Comissão de 
Articulação Federativa, em 2007), a chaga segue aberta, ao menos enquanto não se chega a um consenso sobre a lei que deverá regulamentar o artigo 18, $\S 4^{\circ}$ da Constituição de 1988, para "a criação, a incorporação, a fusão e o desmembramento de municípios".

A referência à participação da sociedade nas instâncias deliberativas metropolitanas também pode receber o mesmo enquadramento teórico, a partir da reflexão sobre a economia política das escalas. Antes, porém, um alerta é indispensável: a literatura sobre gestão democrática tem incorrido, frequentemente, na romantização das pequenas escalas como intrinsecamente mais propícias à democracia urbana. Trata-se do que Purcell (2006, pp. 1923-1925) denomina a "armadilha local":

It refers to the tendency of researchers and activists to assume something inherent about the local scale. The local trap equates the local with 'the good'; it is preferred presumptively over non-local scales. What is defined as good can vary widely. In the democracy literature, of course, democratisation is the primary good. But locally trapped research also desires more sustainable, just or culturally diverse cities. [...] The local trap in the urban democracy literature is founded on the assumption that devolution of authority will produce greater democracy. It is assumed that the more localised governing institutions are, the more democratic they will be. More specifically, the assumption is that the more autonomy local people have over their local urban area, the more democratic and just decisions about that space will be. ${ }^{3}$

Pensar a participação popular na construção política da escala metropolitana requer considerar, em contraste, que os atores do mercado imobiliário e da exploração dos serviços urbanos igualmente anseiam por maior previsibilidade para o desenvolvimento de economias de escala. Portanto, o paradoxo do reescalonamento consiste nesse conflito entre realização das necessidades sociais e monopolização dos mercados regionais, vetores que se contrapõem e cujo resultado dependerá da capacidade de agenciamento dessas novas escalas pelos movimentos sociais na luta pelo direito à cidade, para que não fiquem reféns tão somente da "armadilha local" e de suas limitações.

\section{Dispositivos escalares: planejamento integrado do desenvolvimento urbano}

Dúvida similar emerge no caso da elaboração dos Planos de Desenvolvimento Urbano Integrado. No capítulo IV, a lei trata dos instrumentos para sua efetivação, quais sejam: além do PDUI, planos setoriais interfederativos, fundos públicos, operações urbanas consorciadas interfederativas (com inclusão de novo dispositivo no Estatuto da Cidade de 2001), consórcios públicos, convênios de cooperação, contratos de gestão, parcerias público-privadas interfederativas (art. $9^{\circ}$ ). Destaca-se, justamente, o PDUI como o único obrigatório, que deverá ser instituído por lei estadual revista, ao menos, a cada 10 (dez) anos (arts. 10 e 11), passando previamente pela aprovação da instância colegiada deliberativa da RM ou AU. Requisitos de conteúdo e de procedimento do Plano também foram balizados, no art. 12: 
Art. 12. 0 plano de desenvolvimento urbano integrado de região metropolitana ou de aglomeração urbana deverá considerar o conjunto de municípios que compõem a unidade territorial urbana e abranger áreas urbanas e rurais.

$\S 1^{\circ} 0$ plano previsto no caput deste artigo deverá contemplar, no mínimo:

I - as diretrizes para as funções públicas de interesse comum, incluindo projetos estratégicos e ações prioritárias para investimentos;

II - o macrozoneamento da unidade territorial urbana;

III - as diretrizes quanto à articulação dos municípios no parcelamento, uso e ocupação no solo urbano;

IV - as diretrizes quanto à articulação intersetorial das políticas públicas afetas à unidade territorial urbana;

V - a delimitação das áreas com restrições à urbanização visando à proteção do patrimônio ambiental ou cultural, bem como das áreas sujeitas a controle especial pelo risco de desastres naturais, se existirem; e

VI - o sistema de acompanhamento e controle de suas disposições.

$\S 2^{\circ}$ No processo de elaboração do plano previsto no caput deste artigo e na fiscalização de sua aplicação, serão assegurados: I - a promoção de audiências públicas e debates com a participação de representantes da sociedade civil e da população, em todos os municípios integrantes da unidade territorial urbana;

II - a publicidade quanto aos documentos e informações produzidos; e

III - o acompanhamento pelo Ministério Público.

Nota-se que foi transportada, para os PDUls, a mesma metodologia de democracia participativa aplicável aos Planos Diretores Municipais, conforme o Estatuto da Cidade. Com ainda maiores dificuldades, não há dúvida, para assegurar efetiva participação popular em escala regional-metropolitana, num processo sob a condução de entes diversos e, potencialmente, divergentes, o que não invalida a diretriz, ao contrário, instiga à reflexão: como fomentar o engajamento dos atores sociais, organizados ou dispersos, na elaboração de um documento dessa envergadura? Estamos diante do desafio de articular escalas espaciais e desmistificar paroquialismos:

0 espaço cotidiano seria, assim, a menor escala de um exercício concreto do direito à cidade entendido como direito coletivo de transformá-la. A autonomia na sua produção implica que grupos locais e microlocais determinem seus processos e desenvolvam-nos ao longo do tempo. [...] Assim como as atividades especializadas não são da ordem da vida cotidiana, mesmo que muita gente se envolva com elas diariamente, um grande equipamento urbano não é um espaço cotidiano segundo essa definição, mesmo que muitos 0 frequentem todos os dias. Só cabem no espaço cotidiano assim definido porções urbanas cuja influência seja relativamente limitada. No entanto, como determinar esse limite? E como evitar o paroquialismo? Como fugir do fechamento dessas porções urbanas sobre si mesmas que, no pior dos casos, resulta em guetos com autoritarismos locais e sem nenhuma articulação política mais ampla? (Klapp, 2012, pp. 569-570)

Nesses termos, a apropriação e o agenciamento das escalas regionais pela comunidade dependerão de uma adequada tradução, para o público leigo, do impacto da regulação supralocal em seu espaço cotidiano. Doutro modo, dificilmente se poderá esperar participação interessada. Os canais de diálogo com a 
população também terão de ser reinventados, visto que audiências públicas, por exemplo, penam com limitações notórias. Meios digitais de planejamento colaborativo poderão ser experimentados para complementar, sem substituir, os instrumentos mais convencionais de participação presencial. Enfim, tanto sociedade civil como atores estatais terão de estar dispostos ao "aprendizado social" que decorre dessa interação interessada no laboratório do planejamento urbano (Friedmann, 1987).

Quanto ao macrozoneamento da unidade territorial urbana (art. 12, $\left.\S 1^{\circ}, \mathrm{II}\right)$, ao mesmo tempo que sinaliza a orientação supramunicipal para o uso e ocupação do solo das RMs e AUs, ele necessita de medidas detalhadas e reguladas quanto ao disciplinamento dessas funções, que incluam índices e parâmetros, que mapeiem permissões e restrições, com especial atenção às áreas fronteiriças dos municípios. Exigirá, ainda, uma articulação dos municípios nessas definições e uma rigorosa fiscalização no seu cumprimento, respeitando as diretrizes e os objetivos do plano metropolitano. Será, talvez, a tão almejada oportunidade de se harmonizarem regimes contraditórios entre municípios limítrofes.

Só assim os planos de desenvolvimento integrado deixarão de ser documentos de gabinete ou inócuas peças de literatura ficcional, tornando-se produtos de construção coletiva, participativa, pactuada e de observância obrigatória pelos estados (a assumirem sua missão no planejamento de unidades complexas, como as aglomerações urbanas) e pelos municípios (a se posicionarem como parcelas dessas grandes cidades contínuas, mas fragmentadas político-administrativamente). Se, conforme Ribeiro, Santos Junior e Rodrigues (2015, p. 3), a elaboração e a implementação desses planos pode "ser um processo promissor de congregar as forças sociais e políticas das metrópoles em torno de objetivos comuns e, dessa forma, desencadear um mecanismo de transformação do território funcional e em território político", a (ausência de) vontade política para tanto já dá mostras de desacelerar esse processo. A recente medida provisória 818/2018 prorrogou de janeiro de 2018 para dezembro de 2021 o prazo para elaboração e aprovação dos PDUls para as RMs e Aus preexistentes ao Estatuto (art. 21, I 'b'), afastando, até lá, a hipótese de responsabilização por improbidade administrativa dos governadores estaduais e demais agentes públicos. Nada obstante, a lei n. 13.683/2018, advinda da conversão da mencionada MP, com alterações legislativas, terminou por revogar integralmente 0 art. 21, lançando por terra os prazos e as hipóteses de improbidade administrativa, demonstração cabal da recalcitrância política quanto à questão metropolitana.

Outro fator a influenciar os vetores desse processo, obviamente, e sua própria existência é a capacidade de investimentos disponível. Os custos relativos à elaboração do PDUI, a montagem e manutenção de sistemas de informação, o financiamento da estrutura técnica da entidade metropolitana, a implementação das diretrizes das FPICs, entre outras ações, requerem recursos inexistentes nos quadros atuais. Nesse contexto, por óbvio, o veto presidencial aos fundos específicos para essa política recebeu severas críticas dos estudiosos. Royer (2015) enfatiza que "em um quadro de austeridade fiscal permanente para a gestão pública, a definição do funding do desenvolvimento urbano integrado é primordial e desafia as boas intenções da lei". A seu turno, Frota 
(2015), ressaltando as várias soluções não pacíficas para suprir esse déficit de financiamento, comenta:

Independentemente da existência de um fundo nacional, o modelo baseado simplesmente em repasses voluntários não vincula os entes a transferirem percentuais mínimos do seu orçamento nem assegura que todos contribuirão. Portanto, é incapaz de garantir a continuidade dos serviços metropolitanos. Além disso, no âmbito do financiamento, esse modelo equipararia as regiões metropolitanas aos consórcios públicos, 0 que não faz sentido diante das diferentes naturezas jurídicas e competências de cada um.

Talvez mais tormentosas do que o próprio gargalo do financiamento sejam as alternativas polêmicas viabilizadas pelo Estatuto da Metrópole em seu art. $9^{\circ}$, IV e X: operações urbanas consorciadas interfederativas (OUCS) e parcerias público-privadas interfederativas (PPPs). As OUCs, presentes desde o Estatuto da Cidade (lei n. 10.257/2001) com essa nomenclatura, já são instrumento conhecido do urbanismo brasileiro, nem sempre por seus benefícios sociais. Ao contrário, tanto elas como as PPPs têm sido alvos de atenção e preocupação, devido a seus efeitos nefastos na ordem urbana (Fix, 2000). As iniciativas em curso remetem a impactos de gentrificação, flexibilização e mercantilização do espaço, sofrendo, atualmente, oposição ferrenha dos movimentos sociais de vários segmentos. 0 tipo de agenciamento que se fará desses novos dispositivos de reescalonamento também é, a nosso ver, objeto prioritário de uma agenda de pesquisa "escalar" crítica.

\section{Conclusão: da escala à jurisdição ou como se territorializa o estado}

Cartas na mesa, volvamos às inquietações inaugurais: até que ponto pode o reescalonamento da política urbana intentado pelo Estatuto da Metrópole incidir efetivamente nos padrões contemporâneos de produção social do espaço? Até que medida ele poderá ser apropriado para a concretização do princípio da justa distribuição de ônus e benefícios do processo de urbanização, insculpido no art. $2^{\circ}$ do Estatuto da Cidade? Como se (re)territorializa o estado, nessas condições, sob a forma de uma jurisdição regional? Trata-se de uma arena fértil para os atores da política urbana e de um laboratório rico para a pesquisa aplicada. Um laboratório, ademais, no qual a própria escala e recortes convencionalmente adotados nas pesquisas talvez devam ser questionados, se quisermos pensá-los como "escalas da justiça" (Fraser, 2009).

Como salientamos, ao recortar as RMs e AUs, nos termos previstos pela Constituição Federal de 1988, incluindo entre elas as aglomerações situadas em regiões de fronteiras, 0 Estatuto da Metrópole fica muito aquém do que exige a diversidade de configurações espaciais que permeiam o processo de metropolização brasileiro. ${ }^{4}$ A despeito disso, o Estatuto da Metrópole tende a revigorar todo um campo de pesquisa que se debruça sobre a historicidade e plasticidade dos processos escalares, desnaturalizando os sentidos do "local" e do "regional". Porque o "local" não pode ser o "metropolitano" ? Conforme Vainer (2006, p. 27): 
A historicidade dos processos escalares está posta como uma permanente advertência para que evitemos o congelamento confortável das escalas, que, por exemplo, faz de termos como "lugar" ou "local" noções absolutamente ideológicas, destituídas de qualquer consistência conceitual. De que "local" se fala quando se fala de desenvolvimento local: do município brasileiro, da aldeia tailandesa, da comunidade tribal indiana, do county norte-americano, da comuna francesa?

Seguindo essa trilha, ou melhor, essa encruzilhada em que se intersectam direito e espaço, pode-se repensar os sentidos da jurisdição não somente como atividade judicial de administração dos conflitos, mas como os variados modos de territorialização do estado. Nessa acepção, a jurisdição tem uma história cúmplice com a formação de identidades políticas, instituindo fronteiras que (re)produzem cortes sociais, "tipos" de cidadãos e relações de status:

Territorial jurisdiction produces political and social identities. Jurisdictions define the identity of the people that occupy them. The jurisdictional boundary does more than separate territory; it also separates types of people: native from foreign, urbanites from country folk, citizen from alien, slave from free. [...] Hence, territorial identities are in an important sense remnants of the era before the modern hegemony of contractual social relations chronicled by Sir Henry Maine. Like the social positions of the family, they are largely involuntary relationships of status. (Ford, 1999, pp. 844-845) ${ }^{5}$

Enfatizamos, portanto, que, como pano de fundo e artefato em disputa, é de jurisdição e de seus efeitos na "governança" regional (entendida menos como o puro "governo" do que como um determinado arranjo mais ou menos estável de partilha do poder) que fala o Estatuto da Metrópole. Se reificar as escalas institucionalizadas é cair na "armadilha territorial" do estado moderno, ${ }^{6}$ o esforço para politizá-las implica necessariamente um (re)escalonamento da própria política urbana não isento de riscos. ${ }^{7}$ Longe de uma preocupação exclusivamente pragmática, a rentabilidade teórica do debate escalar espraia-se para outros campos, como o epistemológico, e, qual sugere Strathern (2004), pode conduzir à necessidade de escalonar (scaling) a própria perspectiva das(os) pesquisadoras(es) desse campo. Se escalas são coisas que se fazem e não existem por si, assim também é a vida dos conceitos. Dessa forma, pensar a escala urbano-regional como possível escala de justiça é objeto e projeto do direito à cidade. 


\section{[I] https://orcid.org/0000-0003-3261-6726}

Universidade Federal do Paraná, Programa de Pós-Graduação em Direito. Curitiba, PR/Brasil Observatório das Metrópoles, núcleo Curitiba. Curitiba, PR/Brasil.

hoshino.thiago@gmail.com

\section{[II] https://orcid.org/0000-0003-1702-0617}

Instituto de Pesquisa Econômica Aplicada, Diretoria de Estudos e Políticas Regionais, Urbanas e Ambientais. Brasília, DF/Brasil.

Observatório das Metrópoles, núcleo Curitiba. Curitiba, PR/Brasil.

rmoura.pr@gmail.com

\section{Notas}

(1) Não se pode olvidar, nesse processo, o protagonismo de atores de pressão da sociedade civil organizada, como o Fórum Nacional de Reforma Urbana.

(2) "Vigora no direito urbanístico um princípio da coesão dinâmica de suas normas, que exige uma coerência teleológica entre elas, como condição para que os resultados pretendidos sejam alcançados. Assim sendo, o planejamento deixa de ser uma faculdade para converter-se em uma obrigação do Poder Público" (Pinto, 2005, p. 244).

(3) "Refere-se à tendência dos pesquisadores e ativistas de assumir algo inerente à escala local. A armadilha local iguala o local com "o bem"; é preferível presumivelmente sobre escalas não locais. O que é definido como bom pode variar muito. Na literatura sobre democracia, é claro, a democratização é o bem primário. Mas a pesquisa localmente presa também deseja cidades mais sustentáveis, justas ou culturalmente diversas. [...] A armadilha local na literatura sobre democracia urbana é fundada no pressuposto de que a devolução de autoridade produzirá maior democracia. Supõe-se que quanto mais localizadas as instituições governamentais, mais democráticas elas serão. Mais especificamente, a suposição é que, quanto mais autonomia as pessoas locais tiverem sobre sua área urbana local, mais democráticas e justas serão as decisões sobre esse espaço." (Tradução dos autores)

(4) Grandes arranjos espaciais descontínuos, que reúnem conjuntos de aglomerações e centros, por vezes mais de uma metrópole, ainda estão por ser pensados. Essas novas categorias vêm sendo contempladas pela teoria urbana e por estudos empíricos nacionais e internacionais, pois assumem papéis de comando regional e até nacional na divisão socioespacial do trabalho e oportunidades, reúnem massas expressivas de população e as condições contraditórias de poder político-econômico contrastadas com grandes volumes de demandas desatendidas. Sua contínua expansão física dificulta a extensão de infraestruturas e a oferta suficiente de serviços, envolve um número cada vez maior de municípios e complexifica a articulação para o exercício de funções públicas de interesse comum e da gestão regionalmente integrada, ampliando o número de entes carentes de novos modelos de governança interfederativa. 
(5) “A jurisdição territorial produz identidades políticas e sociais. Jurisdições definem a identidade das pessoas que as ocupam. O limite jurisdicional faz mais do que separar o território; separa também tipos de pessoas: nativas de estrangeiras, urbanas de gente do campo, cidadãs de estrangeiras, escravas de livres. [...] Assim, as identidades territoriais são, em um sentido importante, remanescentes da era anterior à moderna hegemonia das relações sociais contratuais, narrada por Sir Henry Maine. Como as posições sociais da família, elas são, em grande parte, relações involuntárias de status." (Tradução dos autores)

(6) "The first assumption, and the one that is most fundamental theoretically, is the reification of state territorial spaces as fixed units of secure sovereign space. The second is the division of the domestic from the foreign. The third geographical assumption is of the territorial state as existing prior to and as a container of society. Each of these assumptions is problematic, and increasingly so. Social, economic, and political life cannot be ontologically contained within the territorial boundaries of states through the methodological assumption of 'timeless space'." (Agnew, 1994, pp. 76-77)

(7) Não se pode olvidar que também interesses puramente de "economia de escala" estão aptos a mobilizar esta última: “[...] Há que se matizar o que está por trás do agenciamento da escala metropolitana, apontando quais os principais interesses que informam a transformação da política urbana-regional nos moldes da governança metropolitana interfederativa. Ao longo da história político-institucional brasileira, percebe-se que a forma de agenciamento da escala metropolitana variou de acordo com o modelo de desenvolvimento econômico e alinhamentos conjunturais, não necessariamente atentos à justiça socioespacial como valor finalístico" (Fanzoni e Hoshino, 2015, p. 105).

\section{Referências}

AGNEW, J. (1994). The Territorial Trap: The Geographical Assumptions of International Relations Theory. Review of International Political Economy, v. 1, n. 1, pp. 53-80.

ARRETCHE, M. (2004). Federalismo e políticas sociais no Brasil: problemas de coordenação e autonomia. São Paulo em Perspectiva, v. 18, n. 2, pp. 17-26. Disponível em: http://www.scielo. br/scielo.php?script=sci_arttext\&pid=S0102-88392004000200003\&lng=en\&tlng=pt. 10.1590/ S0102-88392004000200003. Acesso em: 15 maio 2018.

BRASIL (2015). Mensagem n. 13, de 12 de janeiro. Presidência da República. Casa Civil. Subchefia para Assuntos Jurídicos. Disponível em: http://www.planalto.gov.br/ccivil_03/_Ato2015-2018/2015/ Msg/VEP-13.htm. Acesso em: 15 maio 2018.

BRASIL (2015). Lei n. 13.089 de 12 de janeiro. Disponível em: http://www.planalto.gov.br/ccivil_03/_ ato2015-2018/2015/lei//13089.htm. Acesso em: 14 maio 2018.

BRASIL. Constituição (1967). Disponível em: http://www.planalto.gov.br/ccivil_03/constituicao/ constituicao67.htm. Acesso em: 14 maio 2018.

BRASIL. Constituição (1988). Disponível em: http://www.planalto.gov.br/ccivil_03/constituicao/ constituicao.htm. Acesso em: 14 maio 2018. 
BRASIL. Lei n. 10.257 de 10 de julho de 2001. Disponível em: http://www.planalto.gov.br/ccivil_03/ leis/leis_2001/I10257.htm. Acesso em: 14 maio 2018.

BRASIL. Lei Complementar n. 14 de 8 de junho de 1973. Disponível em: http://www.planalto.gov.br/ ccivil_03/leis/Icp/lcp14.htm. Acesso em: 14 maio 2018.

BRASIL. Lei Complementar n. 20 de 1o de julho de 1974. Disponível em: http://www.planalto.gov.br/ ccivil_03/leis/Icp/lcp20.htm. Acesso em: 14 maio 2018.

BRASIL.STF - Supremo Tribunal Federal (1998). ADI: 796 ES, Relator: Ministro Néri da Silveira. Data de Julgamento: 2/2/1998, Tribunal Pleno.

(2002). ADI: 1841 RJ, Relator: Carlos Velloso. Data de Julgamento: 1ㅇ/8/2002, Tribunal Pleno.

(2013). ADI: 1.842 RJ, Relator: Ministro Gilmar Mendes. Data de Julgamento: 6/3/2013, Tribunal Pleno.

COSTA, M. A. e TSUKUMO, I. T. L. (2013). “Para uma análise-síntese: uma proposta tipológica para os sistemas de gestão das regiões metropolitanas do Brasil”. In: COSTA, M. A. e TSUKUMO, I. T. L. (orgs.). 40 anos de regiões metropolitanas no Brasil. Capítulo 1, Parte I. Brasília, Ipea, pp. 15-44 (Série Rede Ipea. Projeto Governança Metropolitana no Brasil, v. 1).

COX, K. R. (2010). The Problem of Metropolitan Governance and the Politics of Scale. Regional Studies, v. 44, n. 2 , pp. $215-227$.

DELANEY, D. e LETTNER, H. (1997). The political construction of scale. Political Geography, v. 16, n. 2, pp. 93-97.

DRUMMOND, M. V. D. e SILVEIRA, L. R. G. (2014). “A gestão do território na Região Metropolitana de Belo Horizonte". In: COSTA, M. A. e MARGUTI, B. O. (orgs.). Funções públicas de interesse comum nas metrópoles brasileiras: transportes, saneamento básico e uso do solo. Brasília, Ipea, pp. 85-110.

FIX, M. (2000). A “fórmula mágica” da parceria público-privada: operações urbanas consorciadas em São Paulo. Versão atualizada. Original publicado em: Cadernos de Urbanismo, n. 3. Rio de Janeiro, Prefeitura Municipal do Rio de Janeiro. Disponível em: http://www.usp.br/fau/depprojeto/ labhab/biblioteca/textos/fix_formulamagicaparceria.pdf. Acesso em: 11 dez 2017.

FORD, R. T. (1999). Law's Territory (A History of Jurisdiction). Law Review. Michigan, v. 97, n. 4, pp. 843-930.

FRANZONI, J. A. e HOSHINO, T. de A. P. (2015). Da urbanização periférica ao direito à metrópole: a lei 13089/2015 no reescalonamento da política urbana. Revista Brasileira de Direito UrbanísticoRBDU. Belo Horizonte, ano 1, n. 1, pp. 103-132.

FRASER, N. (2009). Scales of justice: reimagining political space in a globalizing world. Nova York, Columbia University Press.

FRIEDMANN, J. (1987). Planning in the Public Domain: from knowledge to action. Princeton, Princeton University Press.

FROTA, H. B. (2015). Estatuto da Metrópole: o gargalo do financiamento. Disponível em: https:// observasp.wordpress.com/2015/06/10/estatuto-da-metropole-o-gargalo-do-financiamento/. Acesso em: 11 jun 2015.

GRAU, E. R. (1974). Regiões Metropolitanas: Regime Jurídico. São Paulo, Bushatsky. 
IPEA - INSTITUTO DE PESQUISA ECONÔMICA APLICADA (2002). Configuração atual e tendências da rede urbana do Brasil. Brasília, Convênio IPEA, IBGE, Unicamp/le/Nesur (Série Caracterização e Tendências da Rede Urbana do Brasil, 1).

JESSOP, B. (2018). "Dinâmica do regionalismo e do globalismo: uma perspectiva de economia política crítica”. In: BRANDÃO, C. A.; FERNÁNDES, V. R. e RIBEIRO, L. C. de Q. (orgs.). Escalas espaciais, reescalonamentos e estatalidades: lições e desafios para América Latina. Rio de Janeiro, Letra Capital/Observatório das Metrópoles.

KLAPP, S. (2012). Direito ao espaço cotidiano: moradia e autonomia no plano de uma metrópole. Cadernos Metrópole. São Paulo, v. 14, n. 28, pp. 463-483.

KLINK, J. (2013). "Por que as regiões metropolitanas continuam tão ingovernáveis? Problematizando a reestruturaçãoe oreescalonamento doestadosocialdesenvolvimentista em espaçosmetropolitanos". In. FURTADO, B. A.; KRAUSE, C. e FRANÇA, K. C. B. de (eds.). Território metropolitano, políticas municipais: por soluções conjuntas de problemas urbanos no âmbito metropolitano. Brasília, Ipea.

MOURA, R. e CARVALHO, I. (2012). Estatuto da Metrópole: onde está a Região Metropolitana? Boletim Informativo Observatório das Metrópoles, ano III, n. 266, 12/12. Disponível em: http:// observatoriodasmetropoles.net/index.php?option=com_k2\&view=item\&id=455\%3Aestatutoda-metr\%C3\%B3pole-onde-est\%C3\%A1-a-regi\%C3\%A3o-metropolitana\%3F\&ltemid=165\&lang= pt. Acesso em: 10 maio 2018.

MOURA, R. e FIRKOWSKI, O. (2008). Estatuto da Metrópole - contribuição ao debate. Boletim Informativo Observatório das Metrópoles, 9/4/2008. Disponível em: http://www.observatoriodasmetropoles. ufrj.br/download/ESTATUTO-METROPOLE_Rosa_Olga.pdf. Acesso em: 19 abr 2018.

MOURA, R. e HOSHINO, T. A. P. (2015). Estatuto da Metrópole: o que o Paraná tem a ver com isso? Site da Frente Mobiliza Curitiba, publicado em Artigos, em 26/1/2015. Disponível em: http://www. mobilizacuritiba.org.br/2015/01/26/artigo-estatuto-da-metropole-o-que-o-parana-e-curitibatem-a-ver-com-isso/. Acesso em: 15 maio 2018.

NEGRI,A.(2010). Dispositivometrópole:a multidãoea metrópole. Revista LugarComum,n. 25-26, pp. 201208. Disponível em: http://uninomade.net/wp-content/files_mf/110810120930Dispositivo\%20 metr\%C3\%B3pole\%20-\%20A\%20Multid\%C3\%A3o\%20e\%20a\%20metr\%C3\%B3pole\%20-\%20 Antonio\%20Negri.pdf. Acesso em: 11 maio 2018.

OBSERVATÓRIO DAS METRÓPOLES (2009). Arranjos Institucionais para a Gestão Metropolitana. Relatório de Pesquisa. Projeto Observatório das Metrópoles “Território, coesão social e governança democrática: Rio de Janeiro, São Paulo, Belo Horizonte, Curitiba, Porto Alegre, Salvador, Recife, Belém, Natal, Goiânia, Maringá”. CNPq - Institutos do Milênio, out. 2009. Disponível em:http:// www.observatoriodasmetropoles.ufrj.br/relatorio_arranjos_gestao_metropolitana.pdf.Acesso em: 4 abr 2018).

(2013). Níveis de integração dos municípios brasileiros em RMs, RIDEs e AUs à dinâmica da metropolização. Relatório de Pesquisa, dez. 2012. Disponível em: http:// observatoriodasmetropoles.net/download/relatorio_integracao.pdf. Acesso em: 20 maio 2015).

PINTO, V. C. (2005). Direito Urbanístico: Plano Diretor e Direito de Propriedade. São Paulo, Editora Revista dos Tribunais.

PURCELL, M. (2006). Urban Democracy and the Local Trap. Urban Studies, v. 43, n. 11, pp. 1921-1941. 
RIBEIRO, L. C. de Q.; SANTOS JUNIOR, O. A. dos e RODRIGUES, J. M. (2015). Estatuto da Metrópole: o que esperar? Avanços, limites e desafios. Boletim Informativo Observatório das Metrópoles, ano IV, n. 379, 24-3-2015. Artigos. Disponível em: http://www.observatoriodasmetropoles.net/index. php?option=com_k2\&view=item\&id=1148\%3Aestatuto-da-metr\%C3\%B3pole-avan\%C3\%A7oslimites-e-desafios\&Itemid=180\&lang=pt. Acesso: 10 abr 2018.

ROYER, L. (2015). O Estatuto da Metrópole e seu financiamento. Disponível em: https://observasp. wordpress.com/2015/03/24/o-estatuto-da-metropole-e-seu-financiamento/.Acesso em: 15 maio 2018.

SANTOS, M. de O. (2018). “Interpretando o Estatuto da Metrópole: comentários sobre a Lei 13.089/2015". In: MARGUTI, B. O. M.; COSTA, M. A. e FAVARÃO, C. B. Brasil Metropolitano em Foco: desafios à implementação do Estatuto da Metrópole. Brasília, Ipea.

STRATHERN, M. (2004). Partial connections. Walnut Creek, Altamira Press.

TORREÃo, G. (2012). Discussão do Projeto de Lei № 3.460/2004 - Estatuto da Metrópole. In: SEMINÁRIO O ESTATUTO DA METRÓPOLE E A QUESTÃO METROPOLITANA. SEDUR-BA, 18 de outubro. Não publicado.

VAINER, C. B. (2006). Lugar, região, nação, mundo: explorações históricas do debate acerca das escalas da ação política. Revista Brasileira de Estudos Urbanos e Regionais, v. 8, n. 2.

Texto recebido em 18/out/2018

Texto aprovado em 20/fev/2019 